\title{
Significance of Blocked and Recovered Memories in Psychotherapy
}

\author{
Pankhuri Aggarwal ${ }^{1 *}$
}

\section{ABSTRACT}

Validity of blocked memories and subsequently recovering those memories has long been a subject of debate in the field of Psychology. These memories are often viewed in contrast to manufactured memories, although researches have simultaneously indicated that both are inseparable from one another. Given the blurred boundaries between the two, it becomes essential on the part of the psychotherapist to investigate during the process of assessment as to whether his/her client's recalled memories during the course of therapy are truly authentic or confabulated (both due to intentional and unintentional reasons) because of its understandable implications for therapy or otherwise. It is also important to examine the possibility of blocking traumatic memories with psychological processes such as dissociation and repression. More often than not, therapy is directed towards recovering traumatic memories of the past, which if not accurate and authentic, may defeat the very purpose of therapeutic contact. This paper reviews research studies from two opposing viewpoints, one which exerts the existence of blocked and recovered memories and the other which attempts to claim its inauthenticity, while emphasizing what the researchers' term as false memories. The author attempts to bring the two views together in the light of suggesting future directions for research and therapy.

Keywords: Blocked Memories, False Memories, Repression

Validity of blocked and recovered memories, a phenomenon originally studied by Sigmund Freud and Pierre Janet, has direct applications in the field of Psychology probably because of its role in the aetiology of clinical disorders especially dissociative disorders and post-traumatic stress disorder. By blocked and recovered memories, Gleaves et al. (2004) refer to incidents in which well-established memories are transformed into inaccessible material for some undefined period of time, post which these essentially intact memories become available for recall.

A study by Loftus and Herzog (1991) revealed that the therapists undoubtedly believed their clients' claims (mostly because of their overly emotional and painful content), from their presenting problems to their conception of the precipitating factors, and accept them at face

\footnotetext{
${ }^{1}$ Research Scholar, Tata Institute of Social Sciences, Mumbai, India

*Responding Author

(C) 2016, P Aggarwal; licensee IJIP. This is an Open Access Research distributed under the terms of the Creative Commons Attribution License (http://creativecommons.org/licenses/by/2.0), which permits unrestricted use, distribution, and reproduction in any Medium, provided the original work is properly cited.
} 


\section{Significance of Blocked and Recovered Memories in Psychotherapy}

value, as they do not have substantial evidence to believe otherwise. Especially while formulating psychotherapeutic conceptualizations of their clients' illnesses, it seems ironical that therapists rarely engage in independent corroboration of their clients' autobiographical narratives, in order to distinguish the same from false memories; something that has serious implications for therapy (Kihlstrom, 2004).

False memories refer to the experience of having a memory of an event which did not occur in reality. The difference between authentic and false memories lies in the correspondence of the recalled memory with objective reality outside. This differentiation is easier understood than done, probably because past events, inferences drawn and suggestions taken are often not stored as independent memory representations in the brain and therefore it is extremely difficult to distinguish these manufactured memories from factual ones (Gleaves et al., 2004).

It is unfortunate that even if the therapists are unable to elicit the repressed material during assessment, they may still conclude that the event may be so traumatic for their clients that at the moment, given the circumstances, it is less likely that the memories could be brought to consciousness.

Given the scenario, it becomes extremely essential to address certain critical questions. Are all severe mental illnesses characterised by early traumatic childhood experiences? Is it always true that people who are unable to recall early childhood events during therapy are necessarily repressing? How common is it for childhood traumatic memories to be blocked? Does blocked memory act like a dormant volcano, constantly threatening to erupt into the consciousness of an individual during stressful times? When these memories surface, what do they look like? When the memories emerge in the therapeutic set up, what should the therapists' stance be like? What about those times when the retellings are a mere lie, or misremembered portion of the client's lived reality? How credible are blocked memories (both in degree and extent) as opposed to memories which were never blocked? If the recalled memories are not authentic, where exactly do they come from? Is it possible to inject a memory of something that never occurred in reality?

\section{Arguments favouring the authenticity of blocked and recovered memories}

Gleaves et al. (2004) posits that under few conditions, due to severe stressful circumstances, suppression or blocking of memory may take place, which later in the course of life be recovered with the help of the individual's memory. There are numerous studies and research evidences about people who have in therapy managed to recall some earlier previously inaccessible traumatic life experience (Erdelyi, 1985; Rieker \& Carmen, 1986; Schuker, 1979; Williams, 1987). Freud. (1953) has done tremendous work on childhood amnesia or what is popularly accepted view that all humans undergo a poverty of recollection of thoughts for the initial few years in life. 


\section{Significance of Blocked and Recovered Memories in Psychotherapy}

Gleaves et al. (2004) further assert that though routine false memories as opposed to actual traumatic memories are comparatively easier to create, it is far more difficult to convince a person that a traumatic event has taken place in his/her childhood years when the reality is the exact opposite.

Further, empirical evidence for memory blocking and recall comes from various experimental paradigms including tip of the tongue phenomenon (Jones, 1989), negative priming effects (Tipper, 1985), recovery from posthypnotic amnesia (Kihlstorm, 1987), directed forgetting and recovery (Bjork \& Bjork, 1996), spontaneous recovery from retroactive interference (Wheeler, 1995), memory inhibition through executive control (Anderson \& Green, 2001), retrieval induced forgetting (Anderson, Bjork \& Bjork, 1994), output interference and recovery (Brown \& Smith, 1992) and blocking in implicit memory (Lustig \& Hasher, 2001).

\section{Arguments against the authenticity of blocked and recovered memories}

Holmes (1990) in his literature review concluded that despite six decades of research work in the field, there has not yet been any controlled laboratory experiment that could support the phenomenon of repression. Holmes further asserted that the concept of repression has not been validated through experimental research and therefore caution must be maintained while making any interpretations especially of clinical work. Furthermore, Kihlstrom (2004) argued that the majority of claims of blocked and recovered memories arise from clinical folklore where peoples' experiences are documented in the form of anecdotal case reports which are often printed in popular media instead of these works arising from reliable and valid clinical experiments or research studies, which would probably hold greater value both in terms of corroboration and accountability for psychotherapists.

Several research experiments confirm that people can be made to recall traumatic memories which did not occur in reality, which may occur due to misinformation effect (Loftus \& Palmer, 1974), intrusion in schema guided recall (Brewer \& Treyens, 1981), hypnotic pseudo-memory (Laurence \& Perry, 1983) or failures of reality monitoring (Johnson \& Raye, 1981).

According to Loftus (1993), due to the harsh reality of childhood traumatic events and consequent formation of childhood traumatic memories, people are probably more likely to think that if such traumatic events occur so often with others, were similar instances also present during their early years of growing up? Further, interacting with therapists who believe in the theory of repression and trauma-related aetiology of disorders; especially clients, who are already exposed to the popular media, are more likely to believe in the same resulting in a wide range of notions about unsubstantiated traumatic hypothesises and heightened prevalence rates of repression. Moreover, a layperson's intuitive theory regarding repressed memories escorts the

societal perspective on this issue, which in turn could impact the views that therapists have about 


\section{Significance of Blocked and Recovered Memories in Psychotherapy}

the same (Loftus, 1993). However, while agreeing to the fact that such traumatic memories may exist in reality, how can one still logically conclude that each such recalled memory is valid?

It is also important to consider that emotional arousal paves way for the release of stress hormones which enhance memory, which implies that any traumatic event should be relatively easily and vividly available to the consciousness rather than the opposite (Anderson \& Green, 2001; Conway, 2001; Holmes, 1990; Levy \& Anderson, 2002). Further, remembrance of these highly emotional memories may actually serve survival value.

On a parallel note, in disorders such as post-traumatic stress disorder, the person's problem is not that he/she has lost the memory of the traumatic event but that he/she is not able to get rid of it, an intrusion that starts impacting his/her daily adapting functioning.

It would probably be misleading to assume that a simple failure to recall means that repression has happened, something that again brings us back to the authenticity of the prevalence rates of repression. Moreover, forgetting in day to day living is extremely common but is not assumed to involve some special mechanism of repression.

\section{Bringing the two ends together}

Certainly, a lot of the details about memories cannot be checked or confirmed. They are almost unfalsifiable and uncheckable because they usually arise from complex memory networks. It would certainly be unethical to subject people to a wide range of traumatic events in order to investigate their memories of the same and distinguish it from memories of non-traumatic events. Further, over time, memories fade, witnesses disappear, and evidences vanish away, making it all the more difficult to reach the 'truth'. Even within recollections, the quality of memories range from highly detailed and vivid to extremely vague, as well as highly old to recent ones. Moreover, there is also a high possibility that most of our memories comprise of remembrances of things told by significant others rather than true memories themselves. To further complicate the issue, some people might be more susceptible to memory suggestions by others, as compared to the rest of the population, bringing a significant role of personality factors into play. Therefore, it is all the more difficult to deduce a blanket rule of validity for all repressed and recalled memories. At times, certain elements of memory retrieval may change over therapy sessions, hence raising further doubts on their authenticity (Loftus, 1993).

Regarding the commonness of blocked traumatic memories, there are no straightforward answers. Asking people about forgetting and recalling of memories have revealed a wide range of disturbing figures from $18 \%$ to $59 \%$. This implies that an extensive scholarly exploration is required to interpret these figures especially because they have serious implications for answering not only psychiatric but legal questions as well (Loftus, 1993).

(C) The International Journal of Indian Psychology, ISSN 2348-5396 (e)| ISSN: 2349-3429 (p) | 175 


\section{Significance of Blocked and Recovered Memories in Psychotherapy}

With respect to the source of recalled memories, they may arise from illusions, fantasies, internal drives, hallucination-mediated screen memories or even be borrowed beliefs, notions, accounts, characters and myths from the outside world. They may also be therapist induced through unintentional suggestions (Ganaway, 1989).

\section{CONCLUSION AND DIRECTIONS FOR FURTHER RESEARCH}

Instead of adopting an extreme position, there is a need to acknowledge that both kinds of recovered memories namely genuine and confabulated ones may exist under different circumstances and therefore one should accept the authenticity and inauthenticity of recalled memories both due to intentional and unintentional reasons.

There is a need to investigate the phenomenon of repressed memories further as most of the clinical research in this field seems to be flawed at one of the two levels, namely, either there has been a failure in demonstrating that the events in question actually occurred or whether the concerned person was truly amnestic or not. Additional research evidence is required to answer questions such as 'How common are confabulated as well as blocked and recovered memories?', 'What circumstances lead to the formation of each kind?' and 'Can the two types be distinguished using some measures?' and so on. Given the dearth of studies in the Indian context, it is suggested that these phenomena are thoroughly examined by researchers in the country.

Further, if the phenomenon of blocked memories truly exists, and retrieval of these memories is viewed as essential in the process of recovery, then psychotherapy should search for innovative ways in which they could address the same in therapy sessions in order to ensure maximum benefit to their clientele.

Extensive research is also required in the field of recall effect and whether more information produced, repeated recollections (as opposed to one time recall) as well as greater levels of confidence while narrating the incident lead to recall of more accurate information or not. Therefore, subsequently therapists must be trained in extracting accurate memories from their clients as much possible in order to reach more accurate clinical inferences. Substantiating theoretical underpinnings with empirical data may be particularly helpful. For instance, interview schedules could be prepared for clients as well as practitioners in order to explore this field of study further and possibly identify the various factors at play.

Given the existence of these phenomena, therapists could initiate the therapeutic process by trusting their clients on their respective memory contents. However, gradually while working with their clients and their memories, therapists could be cautious about part(s) or whole of memory contents that may seem untrue and explore the possible reasons of its manifestation in the clients' lives. They could then decide on the basis of their clients' progress, to whether or not discuss those confabulated stories with them, and collectively explore the underlying reasons for 


\section{Significance of Blocked and Recovered Memories in Psychotherapy}

engaging in the same. While it is crucial that the therapist should attempt to not come across as a disapproving and non-trusting affiliate to his clients, it is simultaneously also important to fulfil the reason for this affiliation at the first place, which is the successful resolution of the clients' internal conflicts.

\section{Acknowledgments}

The author appreciates all those who participated in the study and helped to facilitate the research process.

\section{Conflict of Interests}

The author declared no conflict of interests.

\section{REFERENCES}

Anderson, M. C., \& Green, C. (2001). Suppressing unwanted memories by executive control. Nature, 410, 366-369.

Anderson, M. C., Bjork, R. A., \& Bjork, E. L. (1994). Remembering can cause forgetting: Retrieval dynamics in long-term memory. Journal of Experimental Psychology: Learning, Memory \& Cognition, 20, 1063-1087.

Bjork, R. A., \& Bjork, E. L. (1996). Continuing influences of to-be-forgotten information. Consciousness and Cognition, 5, 176-196.

Brewer, W. F., \& Treyens, J. C. (1981). Role of schemata in memory for places. Cognitive Psychology, 13, 207-230.

Brown, J. M., \& Smith, S. M. (1992, April). Recovery from part-list cuing inhibition. Paper presented at the meeting of the Midwestern Psychological Association, Chicago.

Conway, M. A. (2001). Sensory-perceptual episodic memory and its context: Autobiographical memory. Philosophical Transactions of the Royal Society B: Biological Sciences, 356, 1375-1384

Erdelyi, M. H. (1985). Psychoanalysis: Freud's Cognitive Psychology. New York: Freeman.

Freud, S. (1953). Three essays on the theory of sexuality. In J. Strachey (Ed.), The standard edition of the complete psychological works of Sigmund Freud (Vol. 7, pp. 135-243). London: Hogarth Press, (Original work published 1905)

Ganaway, G. K. (1989). Historical versus narrative truth: Clarifying the role of exogenous trauma in the etiology of MPD and its variants. Dissociation, 2, 205-220.

Gleaves, D. H., Smith, S. M., Butler, L. S., \& Spiegel, D. (2004). False and Recovered Memories in the Laboratory and Clinic: A review of experimental and clinical evidence. Clinical Psychology: Science and Practice, 11 (1), 3-28.

Holmes, D. (1990). The evidence for repression: An examination of sixty years of research. In J. Singer (Ed.), Repression and dissociation: Implications for personality, theory, psychopathology, and health, (pp. 85-102). Chicago: University of Chicago Press.

Johnson, M. K., \& Raye, C. L. (1981). Reality monitoring. Psychological Review, 88, 67-85.

Jones, G. V. (1989). Back to Woodworth: The role of interlopers in the tip of the tongue phenomenon. Memory \& Cognition, 17, 69-76. 


\section{Significance of Blocked and Recovered Memories in Psychotherapy}

Kihlstrom, J. F. (1987). The cognitive unconscious. Science, 237, 1445-1452.

Kihlstrom, J. F. (2004). An unbalanced balancing act: Blocked, recovered, and false memories in the laboratory and clinic. Clinical Psychology: Science and Practice, 11(1), 34-41.

Laurence, J. R., \& Perry, C. (1983).Hypnotically created memory among highly hypnotized subjects. Subjects, 222, 523-524.

Levy, B. J., \& Anderson, M.C. (2002). Inhibitory processes and the control of memory retrieval. Trends in Cognitive Sciences, 6, 299-305.

Loftus, E. F. \& Herzog, C. (1991). Unpublished data. (University of Washington)

Loftus, E. F. (1993). The reality of repressed memories. American Psychologist, 48 (5), 518-537. Washington, USA.

Loftus, E. F., \& Palmer, J. C. (1974). Reconstruction of automobile destruction: An example of the interaction between language and memory. Journal of Verbal Learning and Verbal Behavior, 13, 585-589.

Lustig, C., \& Hasher, L. (2001). Implicit memory is vulnerable to proactive interference. Psychological Bulletin, 127, 618- 628.

Rieker, P. P., \& Carmen, E. H. (1986). The victim-to-patient process: The disconfirmation and transformation of abuse. American Journal of Orthopsychiatry, 56, 360-370.

Schuker, E. (1979). Psychodynamics and treatment of sexual assault victims. Journal of the American Academy of Psychoanalysis, 7, 553-573.

Tipper, S. P. (1985). The negative priming effect: Inhibitory priming by ignored objects. Quarterly Journal of Experimental Psychology: Human Experimental Psychology, 37A, 571590.

Wheeler, M. A. (1995). Improvement in recall overtime without repeated testing: Spontaneous recovery revisited. Journal of Experimental Psychology: Learning, Memory, and Cognition, 10, 733-744.

Williams, L. M. (1987). Reconstruction of an early seduction and its aftereffects. Journal of the American Psychoanalytic Association, 15, 145-163.

How to cite this article: P Aggarwal (2016), Significance of Blocked and Recovered Memories

in Psychotherapy, International Journal of Indian Psychology, Volume 3, Issue 4, No. 68, ISSN:2348-5396 (e), ISSN:2349-3429 (p), DIP:18.01.209/20160304, ISBN:978-1-365-39398-3

(c) The International Journal of Indian Psychology, ISSN 2348-5396 (e)| ISSN: 2349-3429 (p) | 178 